\title{
BIODIREITO COMO LUGAR DE DESENVOLVIMENTO DE PERSPECTIVAS JURÍDICAS PARA A PROTEÇÃO DA VIDA
}

Biolaw as an environment for development of legal perspectives for the protection of life

${ }^{1}$ Universidade de Caxias do Sul. Porto Alegre/RS, Brasil.

Correspondência: Henrique Mioranza Koppe Pereira. E-mail: henriquekoppe@gmail.com.

Recebido em: 02/02/2016. 


\section{Biodireito e bioética: um debate latente dos novos direitos em um novo milênio}

Os debates a que se propõe esta edição da Revista de Direito Sanitário quando suscita as temáticas do biodireito são de uma atualidade ímpar. Diferentemente de pesquisas jurídicas mais tradicionais que revisitam problemáticas que a humanidade já vivenciou em outras épocas, as discussões sobre biodireito passam a ter conceitos definidos e apurados a partir do século XX.

O próprio termo "biodireito" é uma derivação jurídica da bioética, a qual foi cunhada por Van Rensselaer Potter (ou Pötter) em 1971 em sua obra Bioéthics: bridge to the future, objetivando aproximar a ciência das novas questões humanitárias. Potter, ao expor seus estudos, apresentou uma lógica transdisciplinar, que abria as discussões sobre "o agir" visando à ecologia humana como um todo e ao respeito à saúde em seus múltiplos aspectos ${ }^{1}$.

É importante salientar que rapidamente o campo de atuação de sua proposta foi, equivocadamente, reduzido somente a discussões que dizem respeito à biomedicina, devido ao aumento de incidência dessas condutas a partir dos novos desenvolvimentos da biomedicina. Felizmente, muitos debates e pesquisas sobre o assunto foram sendo realizados, até que, em 2001, o Programa Regional de Bioética, vinculado à Organização Pan-Americana de Saúde (OPAS), definiu que a bioética possui um caráter de atuação amplo - incluindo a vida, a saúde e o ambiente como áreas de reflexão - e descartou veementemente a ideia de que a bioética é uma "torre de marfim" que abriga médicos, biólogos ou disciplinas deístas ${ }^{2}$.

Com isso, a reflexão sobre o "agir humano" e, consequentemente, as considerações científicas tecnológicas e jurídicas incorporam a bioética para buscar prioritariamente uma reflexão ética sobre os valores inerentes à vida. Segundo Galvão, esse agir da bioética se define como a ética da vida, que trabalha a serviço da vida ${ }^{3}$.

Dessa forma, os conceitos éticos trabalhados pela bioética com o objetivo de proteger a vida perante às outras ciências utilizam uma estrutura moral para discutir uma conduta em prol do desenvolvimento da vida. Com isso, essas reflexões podem dizer respeito a todas as intervenções na biosfera, e não apenas às intervenções sobre o ser humano, pois não se limitam apenas a uma ciência ou disciplina, e sim abrangem toda complexidade científica que se apresenta na atualidade. Abordando de forma transdisciplinar as ciências e os sistemas sociais:

Pode-se afirmar que a Bioética é um claro exemplo de aproximação a um objeto de estudo comum, multidisciplinar, para onde

${ }^{1}$ POTTER, Van Rensselaer. Bioéthics: bridge to the future. New Jersey: Prentice-Hall, 1971.

${ }^{2}$ PEREIRA, Henrique Mioranza Koppe. Responsabilidade civil do fornecedor de alimentos. 2. ed. Curitiba: Juruá, 2010.

${ }^{3}$ GALVÃO, Antônio Mesquita. Bioética: a serviço da vida. Aparecida: Santuário, 2004. p. 58. 
confluem diversas ciências, além da ética, com suas respectivas perspectivas e metodologias próprias. Neste sentido amplo de sua manifestação empírica, também o direito se integraria nela. Todas essas características acrescentadas ao seu marco ideológico plural e transnacional propendem a que a Bioética se configure como um poderosíssimo, mas ainda - em certo grau - potencial instrumento intelectual de reflexão, de elaboração de critérios de orientação e de ponto de partida para tomada de decisões oponíveis às tentações dos excessos do Estado, dos poderes fáticos difusos de pressão (políticos, econômicos, industriais) e, se for necessário, dos próprios pesquisadores ${ }^{4}$.

Também se aponta a definição de bioética proposta por Junges, que reforça o caráter transdisciplinar e salienta uma importante limitação das reflexões da bioética, que é o caráter iminentemente moral dessa área.

\begin{abstract}
A Bioética é uma área específica com identidade e estatuto epistemológico próprios, que tem como objeto a análise ética de situações e de desafios nos quais estão implicados a vida, em seu sentido amplo, e mais especificamente a saúde humana. Ela tem, por um lado, uma dimensão teórica preocupada com seus pressupostos e fundamentos e, por outro lado, uma dimensão prática de ética aplicada interessada na metodologia para chegar a decisões morais no âmbito da vida e da saúde. Em suas análises, a Bioética tem igualmente uma preocupação com as dimensões sociais dos problemas, levando em consideração aspectos legais e de política pública ${ }^{5}$.
\end{abstract}

A partir desse texto, percebe-se que, para que a bioética tenha sucesso em sua cruzada, é imprescindível sua conexão com políticas públicas e movimentações jurídicas. O que dá origem ao tópico-chave da presente revista: o biodireito.

O biodireito é definido como um subsistema da ciência jurídica que tem a vida como objeto de tutela. Dessa forma, o biodireito não é uma derivação da bioética, mas sim a face jurídica que dialoga diretamente com os dilemas morais discutidos nesta área filosófica ${ }^{6}$.

Uma das funções que esse subsistema desempenha no universo jurídico é a de integrar novos pontos de vista, desenvolvendo uma evolução jurídica

\footnotetext{
${ }^{4}$ ROMEO CASABONA, Carlos Maria. O direito biomédico e a bioética. In: ROMEO CASABONA, Carlos Maria; QUEIROZ, Juliane Fernandes (Orgs.). Biotecnologia e suas implicações ético-jurídicas. Belo Horizonte: Del Rey, 2005. p. 22-23.

5 JUNGES, José Roque. Bioética: hermenêutica casuística. São Paulo: Loyola, 2006. p. 256.

${ }^{6}$ SEMEÃO, Sérgio Abdalla apud FERNANDES, José de Sousa. Bioética, biodireito e religião no diálogo sobre a eutanásia. In: SÁ, Maria de fática Freire de; NAVES, Bruno Torquato de Oliveira (Orgs.). Bioética, Biodireito e o novo Código Civil de 2002. Belo Horizonte: Del Rey, 2002. p. 18.
} 
perante as mudanças sociais ${ }^{7}$. Esse trabalho é de extrema importância, pois vem normatizar a ação humana que apresente consequências diretas ou indiretas à vida, assim como questionar as normas jurídicas obsoletas que continuem em vigência - caracterizando-se, assim, como um movimento transdisciplinar. $\mathrm{O}$ biodireito não se mostra como dispositivo específico e seccionado; pelo contrário, suas normativas se apresentam dispersas entre as diversas áreas do direito, como Penal, Trabalhista, Ambiental, Administrativo, Constitucional, Civil entre outras. É importante salientar que a utilização dos conceitos e das lógicas do biodireito se restringe a questões diretamente relacionadas à vida humana, pois compreende também as discussões que dizem respeito a toda biosfera.

O biodireito não possui o cunho de criar discussões filosóficas sobre seus objetos de atuação, pois isso ocorre em um momento anterior à incidência jurídica - ou seja, em uma reflexão gerada a partir da bioética. É preciso esclarecer, neste momento, que não há entre o biodireito e a bioética uma distinção que os separe, pois um é consequência do outro. A bioética atua na reflexão e na conduta dos indivíduos, fazendo com que o sistema jurídico passe a absorver determinadas posturas e a criar normas jurídicas de acordo com o contexto espaço-temporal. A constituição dessas normas depende do momento social e cultural, pois a norma moral e dogmática está submetida aos pensamentos elaborados dentro desse contexto e de uma subjetividade momentânea. Isso se confirma a partir do crescente número de comitês de bioética ${ }^{8}$.

\section{Objeto de tutela e princípios básicos do biodireito}

Como já se demonstrou, o biodireito é o ramo do direito que discute as normas destinadas a proteger a vida e a saúde humana, sendo, portanto, este o objeto de tutela jurídica dessa área. Todavia, para que seja possível proteger esse bem jurídico, é imprescindível um diálogo transdisciplinar. Ou seja, é necessária uma percepção ampla e sistêmica que possibilite a observação de toda a ecologia do ser humano e de suas implicações para a vida - o que obriga que a reflexão jurídica não seja realizada de forma distanciada ou seccionada de outras áreas de áreas de conhecimento, tampouco que se limite a discussões interdisciplinares superficiais e esporádicas. Mas a ciência jurídica, com o biodireito, deve absorver o entendimento das outras ciências para que as normativas se constituam o mais próximo possível das demandas sociais.

É nobre o objetivo dessa área jurídica, pois protege o bem jurídico mais importante a ser protegido pelo ordenamento jurídico: a vida. A partir dela, inicia-se toda a teia sistêmica que envolve o universo, sendo que a presença do ser humano,

${ }^{7}$ FERNANDES, José de Sousa. op. cit., p. 18.

${ }^{8}$ PEREIRA, Henrique Mioranza Koppe. op. cit. 
como um ente inteligente, e sua percepção racional perante o mundo possibilitam a existência de uma realidade. Sem a vida, tudo se resume à matéria inerte regida por princípios sistêmicos físicos e químicos sem sentido algum, resumidos em mudanças estagnadas, das quais não resulta nenhuma evolução. Assim, a existência equivale ao nada, por negar a presença do ente observador racional, que tem a capacidade de perceber aquilo que o cerca e com ele interage, conceituando o ser como ser e a coisa, como coisa. Deve-se ter consciência de que a vida não é o oposto da morte. A vida, que se encontra como objeto de proteção da bioética, diz respeito a toda a ecologia que envolve a vida, tanto de uma perspectiva individual, quanto social e ambiental. ${ }^{9}$

É oportuno citar aqui o filósofo Junges, que explica dois importantes princípios para se analisarem as temáticas da bioética e do biodireito: o princípio da inviolabilidade e o princípio da intangibilidade ${ }^{10}$.

Ambos são importantes, todavia devem ser observados em conjunto para que não haja prejuízo social, como se poderá verificar a seguir. O primeiro, o princípio da inviolabilidade, tem como lógica entender que a vida é um bem intocável, pois seria um dom ${ }^{11}$ que ninguém possui o poder de dar a outro - dessa forma, pessoa alguma teria o direito de tirá-la de seu semelhante. Em entendimentos deístas, esse conceito estava diretamente ligado à fé e à crença de que Deus seria o único titular de direito para com a vida. De acordo com Junges, "o princípio da inviolabilidade alude uma concepção sacral: a vida humana como propriedade de Deus e o ser humano como seu mero administrador"12. É evidente que, ao se utilizar desse princípio sem uma ponderação, construiu-se um tabu sobre a vida, que afasta categoricamente a aceitação, ou até mesmo a discussão, de atos que possam ameaçar a vida. Todavia, essa vigorosa sede de proteger a vida pode ter um efeito adverso e prejudicar possíveis avanços que representam incrementos para atingir os objetivos do biodireito. Como explana Junges:

O princípio da inviolabilidade é um princípio insuficiente, porque ignora o horizonte existencial no qual as pessoas se movem atualmente e, levado às últimas consequências, pode levar a resultados que atentam contra a vida. A modernidade afirma muito mais direito à autodeterminação, mesmo tratando-se da vida. A vida é um dom (ninguém pode dar a si mesmo a vida), mas, que, uma vez recebido, fica ao encargo e responsabilidade daquele que o possui. Cabe à pessoa dar mais qualidade à vida própria e à dos outros. Hoje, procura-se ter uma visão muito mais generosa de Deus em relação à autonomia do ser humano.

\footnotetext{
${ }_{9}^{9}$ PEREIRA, Henrique Mioranza Koppe. op. cit.

${ }^{10}$ JUNGES, José Roque. Bioética: perspectivas e desafios. São Leopoldo: Unisinos, 1999. p. 113.

${ }^{11}$ Entende-se por "dom" algo - uma característica ou habilidade - que alguém possui sem a intenção ou a vontade de seu possuidor.

${ }_{12}$ JUNGES, José Roque. Bioética: perspectivas e desafios, cit., p. 113.
} 
Dispor da vida e intervir nela não fere o senhorio Deus, se esta ação não for arbitrária ${ }^{13}$.

É interessante que compreender a limitação do princípio da inviolabilidade não quer dizer que este seja descartado, mas sim que deve ser complementado pelo princípio da intangibilidade da vida. Esse princípio possui um entendimento derivado dos imperativos categóricos kantianos, os quais auxiliam a refletir sobre "a vida" e como ela deveria ser de acordo com um ideal de bom em uma perspectiva moral. Com isso, permite-se refletir sobre questões como "que tipo de vida terá um neonatal anencefálico?" Os casos de anencefalia discutidos na Arguição de Descumprimento de Preceito Fundamental - ADPF 54 - são um ótimo exemplo para ilustrar essa questão. Visto que insistir em proteger a vida e a gestação dessas crianças causava um sofrimento social demasiado, justificou-se, juridicamente, $o$ aborto nesses casos.

Frente a essas explanações, Junges coloca que "é necessário saber conjugar as duas abordagens. Em certos momentos, é preferível usar o princípio da sacralidade e, em outros, o da qualidade. Um não deve ser usado para negar o outro".

Dessa forma, utilizar ambos os princípios torna possível realizar discussões como propõe o presente volume da Revista de Direito Sanitário, que apresenta temas como: comércio de produtos biotecnológicos, biobancos e consentimento do indivíduo em relação ao próprio corpo após a morte.

Do ponto de vista jurídico, esses temas atingem diretamente a vida como bem jurídico. E, para que o direito possa regular condutas relacionadas, é estritamente necessário o amadurecimento científico sobre essas questões. Esta não é uma tarefa simples; muitos juristas preferem evitar tais empreitadas devido à sua complexidade e ao mal-estar que criam ao abalarem paradigmas. Todavia, para que se desenvolvam positivamente a sociedade e o direito, os paradigmas devem ser questionados e os tabus, enfrentados.

\section{Referências}

ROMEO CASABONA, Carlos Maria. O direito biomédico e a bioética. In: ROMEO CASABONA, Carlos Maria; QUEIROZ, Juliane Fernandes (Orgs.). Biotecnologia e suas implicações ético-jurídicas. Belo Horizonte: Del Rey, 2005.

FERNANDES, José de Sousa. Bioética, biodireito e religião no diálogo sobre a eutanásia. In: SÁ, Maria de fática Freire de; NAVES, Bruno Torquato de Oliveira (Orgs.). Bioética, Biodireito e o novo Código Civil de 2002. Belo Horizonte: Del Rey, 2002.

${ }^{13}$ Id. Ibid., p. 114. 
GALVÃO, Antônio Mesquita. Bioética: a serviço da vida. Aparecida: Santuário, 2004.

JUNGES, José Roque. Bioética: hermenêutica casuística. São Paulo: Loyola, 2006. . Bioética: perspectivas e desafios. São Leopoldo: Unisinos, 1999.

PEREIRA, Henrique Mioranza Koppe. Responsabilidade civil do fornecedor de alimentos. 2. ed. Curitiba: Juruá, 2010.

POTTER, Van Rensselaer. Bioéthics: bridge to the future. New Jersey: Prentice-Hall, 1971.

Henrique Mioranza Koppe Pereira - Doutor em Direito pela Universidade de Santa Cruz do Sul, com enfoque em políticas públicas; mestre em Direito pela Universidade do Vale do Rio dos Sinos; bacharel em Direito pela Universidade de Caxias do Sul. Professor na Universidade de Caxias do Sul; pesquisador integrante do Grupo de Pesquisa Metamorfose Jurídica da Universidade de Caxias do Sul. Porto Alegre/RS, Brasil.E-mail: henriquekoppe@gmail.com. 